\title{
Relationship among quality of nurses' work life, organizational culture and Turnover Intention at Assiut University Hospital
}

\author{
Fatma Rushdy Mohamed \& Om Hashem Gomaa Ragab \\ Assistant Professor, of Nursing Administration, Faculty of Nursing, Assiut University, Egypt. \\ Lecturer of Nursing, Administration, Faculty of Nursing, Sohag University, Egypt.
}

\begin{abstract}
Introduction: Nurses are amongst the employees whose lives are fully affected by the quality of work life (QWL) as a consequence of dynamic changes in work environment. The aim was to investigate the relationship among nurses' quality of work life, organizational culture and turnover intention at Assiut University Hospital. Design: A correlational descriptive design was used. Setting: four Intensive Care Units classified as follows: Causality Intensive Care Unit, General \& Postoperative ICUs, and Coronary Care Unit (CCU).Subjects: Included all nurses working in aforementioned settings with a total number of 120 nurses. Four tools were used to collect data namely: socio-demographic data sheet, quality of nurses' work life, organizational culture questionnaire, and turnover intention questionnaire. Results: illustrated that nurses' quality of work life scores was highly significant in relation to the department, marital status, organizational culture score, and turnover intention score. Conclusion: This study contributed to understanding the relationships between quality of nurses work life and organizational culture that will lead to turnover intention among the study sample of hospital nurses and found a positive correlation between quality of nurses work life and organizational culture with highly statistically significant relation and between quality of nurses work life and turnover intention. While, there was a negative correlation between turnover intention and organizational culture. Recommendations: Workshops on the quality of work life skills for nurses and nurse managers should be done periodically. In order to lessen intent to turnover for the nursing profession, staff nurses are encouraged to participate in nursing committees, assume leadership roles, and become decision-makers.
\end{abstract}

\section{Key Words: Quality of work life (QWL), Organizational culture, Turnover Intention \& Nurses.}

\section{Introduction}

Indications of work life quality include work absenteeism, work turnover rate, employer-employee conflict, the number of work accidents and overtime (Cole et al., 2005). Previous studies indicated that nurses complain about excessive workload, long working hours, and dissatisfaction with management, poor work conditions, high work-related stress, shift work, inadequate educational and professional development opportunities and tasks other than nursing; in addition, they have to feel of quitting job and inclined to quit their current jobs (Ugur \& Abaan, 2008).

The quality of Working Life is critical for healthcare organizations to attract and retain qualified, committed and motivated employees. The quality of working life refers to an employee's satisfaction with working life. It shows the relationship between employees and their physical, social and economic work environment. It is a multi-dimensional concept and covers an employee's feelings about various dimensions of work. These include the job content, working conditions, fairness and adequate compensation, career development opportunities, task discretion, participation in decision-making, occupational health and safety, work stress, job security, organizational and interpersonal relations and work-life balance (Hsu and Kernohan, 2006, Connell, 2009, Adhikari \& Gautam, 2010 \& Mosadeghrad et al., 2011).

QWL is a comprehensive and general schema which is essential in improving employees' satisfaction, attracting and preserving personnel. It results in positive theories such as increasing profits and provocation. The quality of nurses' work life is influenced by four factors including social, executive, managing situations and specific cultural situations where problems and shortages consequently lead to work dissatisfaction, psychological exhaustion and quitting the job (Mohammadi et al., 2011).

Khodayarian et al., (2008) defined QWL as the ability of employees to satisfy their important personal needs through what they have learned in their organization. In fact, improving the quality of work life will lead to a comprehensive improve for the quality of life of employees in the workplace and is essential in any organization to attract and retain its employees (Dargahi et al., 2012).

It's easily said that every hospital as an organization has a corporate culture. And, as a living organization, people make a hospital work and its cultures tie people together, giving meaning and purpose to their day to day activities and lives. The need to diagnose

Vol , (4) No , (8) August 2016 
and manage corporate culture is growing in importance (Cameron \& Quinn, 1999).

Waters, (2004) defined organizational culture as "the source of motivated and coordinated activities within the organization, activities that serve as a foundation for practices and behaviors that endure because they're meaningful, have a history of working well, and are likely to continue working in the future". While, Kreitner \& Kinicki (2008) stated that organizational culture is "the operating system" of an organization and drives the organization and its action.

In addition, Marques \& Huston, (2009) defined organizational culture as a system of symbols and interactions unique to each organization. It is the ways of thinking, behaving, and believing that members of a unit have in common. Although assessing unit culture is a management function, building a constructive culture, particularly if a negative culture is in place, requires the interpersonal and communication skills of a leader. Way, (2006) stated that it is imperative for health care organization to support a "nurse friendly" culture where nurses are able to perform their roles.

Abdalla,(2009) mentioned three types of culture call the first of these a positive culture which means strong culture in which members are encouraged to interact with others and to approach tasks in proactive way that will help them to meet their satisfaction needs and its based on achievement, second type is medium and weak culture, members in both types interact in reactive ways and approach tasks in forceful ways to protect their status and formality.

A strong organizational culture guides employees in many every day actions. It determines, whether an employee will inconvenience himself or herself to satisfy patients. If the organizational culture is not so strong, employees are more likely to follow their own whims- they may decide to turnover (Korunka et al., 2008). In fact, improving the quality of work life will lead to a comprehensive improve for quality of life of employees in the workplace and is essential in any organization to attract and retain its employees (Dargahi et al., 2012).

\section{Significance of the study}

Quality of life has recently attracted managers' attention who intend to promote their staff quality and decrease nurses' burnout which lead to increase turnover intention. Most existing literature on QWL has been conducted in western cultures. By virtue of cultural variations in terms of working condition, context and staff perception, it remains unclear that which findings could be generalized to other cultural contexts. Enhancement quality of working life for staff is as much needed as improving quality of patients care. Quality of working life is important because it is associated with employee commitment (Farjad \& Varnous, 2013), turnover intentions (Korunka et al., 2008), and quality of life (Drobinic et al., 2010). Individuals' perception and expectations from an organization may have significant implications towards the well-being of an organization, especially organization of a service nature such as the hospital. A better understanding of turnover intention and its relation to the perceived quality of work life and organizational culture is required.

\section{Aim of the study}

The present study aims to investigate the relationship among quality of nurses' work life, organizational culture and turnover intention at Assiut University Hospital.

\section{Research questions}

- What is the relationship between nurses' quality of work life and organizational culture?

- What is the relationship between nurses' quality of work life and turnover intention?

- What are the relationships among nurses' sociodemographic characteristics, organizational culture and turnover intention?

\section{Subject \& Methods}

\section{Study design}

A correlational descriptive design was used.

Setting

- The study was carried out at four Intensive Care Units in Assiut University Hospital which including the following: General \& Postoperative ICUs, Causality Intensive Care Unit, and Coronary Care Unit (CCU).

\section{Subject}

The subject includes all nurses working in aforementioned settings with a total number of 120 nurses.

\section{Data collection tools}

Four tools were used to collect data for this study as follows

- $\mathbf{1}^{\text {st }}$ tool: Socio-demographic data sheet including: age, marital status, educational qualification, years of experience, and department.

- $2^{\text {nd }}$ tool: Quality of nurses' work life (QNWL) questionnaire, which developed by Brook, (2001) to determine nurses' work life quality. The questionnaire consists of 35 items and it has five factors [Work Environment (total score 54), Relations with managers (total score 30), Work Conditions (total score 60), Job perception (total 
score 42), and Support Services (total score 24)]. Each item was scored on the 6-point Likert scale ranging from "strongly disagree (1 point)" and "strongly agree (6 points)".

- $3^{\text {rd }}$ tool: Organizational culture questionnaire, which adopted from Abdalla , (2009). It consisted of (13) statements which profiling three types of culture: strong, medium, and weak, the response was based on five-points Likert scale that ranged from (5) strongly agree to (1) strongly disagree. When the score becoming above 52 organizational culture considered strong. From 51 to 26 considered medium. While, less than 25 was considered weak.

- $4^{\text {th }}$ tool: Turnover intention questionnaire: This developed by Hinshaw \&Atwood, (1984) \& modified by Almalki, (2012). It consisted of (12) statements, the response was measured on the seven-point Likert scale that ranged from (7) strongly agree to (1) strongly disagree.

- The reliability of the three previous tools was assessed in a pilot study by measuring their internal consistency using Cronbach's alpha coefficient method. This turned to be 0.80 for the quality of nurses' work life, 0.92 for organizational culture, and 0.86 for turnover intention, which indicating a high degree of reliability. Validity was measured by five experts in the field of Nursing Administration.

\section{Pilot study}

The pilot study served to test the feasibility, clarity, and practicability of the data collection tools. It was carried out on 20 nurses from different inpatient departments in Assiut University Hospital. The pilot study collected in November 2015. The study subjects included in the pilot study were excluded. Data collected from the pilot study were reviewed and used in making the necessary modifications prior to the finalization of the study tools for data collection.

\section{Fieldwork}

An official permission was obtained from the hospital director, the nursing service administration director, and the head of each Intensive Care Unit before embarking on the data collection. The actual data collection was started in December 2015 and ended in January 2016. The researchers met the eligible nurses, explained to them the purpose of the study, and asked them for their oral consent to participate. Those who agreed to participate were given the tools and asked to fill them out and return them anonymously in the same setting or at most the next day.

\section{Ethical Considerations}

The research protocol was approved by the pertinent authority. Participants' oral consent was obtained after informing them about their rights to participate, refuse, or withdraw at any time. Total confidentiality of any obtained information was ensured. The study maneuver could not entail any harmful effects on participants.

\section{Statistical analysis}

Data entry and statistical analysis were done using SPSS 19.0 statistical software package. Data were presented using descriptive statistics in the form of frequency, percentages, mean and standard deviation Pearson correlation analysis was used for assessment of the inter-relationships among quantitative variables, and Spearman rank correlation for ranked ones. Statistical significance was considered at pvalue $<0.05$. 


\section{Results}

Table (1): Distribution of socio-demographic characteristics of studied nurses at Assiut University Hospital $(\mathbf{n}=120)$.

\begin{tabular}{|c|c|c|}
\hline Socio-demographic characteristics & No. & $\%$ \\
\hline \multicolumn{3}{|l|}{ Department } \\
\hline General ICU & 42 & 35.0 \\
\hline Post-operative ICU & 15 & 12.5 \\
\hline Causality ICU & 32 & 26.7 \\
\hline Coronary ICU & 31 & 25.8 \\
\hline \multicolumn{3}{|l|}{ Age: (years) } \\
\hline $22<25$ & 71 & 59.2 \\
\hline $25<30$ & 27 & 22.5 \\
\hline $30<35$ & 10 & 8.3 \\
\hline $35+$ & 12 & 10.0 \\
\hline Mean \pm SD & \multicolumn{2}{|c|}{$2.74 \pm 0.98$} \\
\hline \multicolumn{3}{|l|}{ Educational qualification } \\
\hline Diploma degree of Nursing & 43 & 35.8 \\
\hline Technical Institute of Nursing & 57 & 47.5 \\
\hline Bachelor degree of Nursing Science & 20 & 16.7 \\
\hline \multicolumn{3}{|l|}{ Marital status } \\
\hline Single & 62 & 51.7 \\
\hline Married & 55 & 45.8 \\
\hline Divorced & 3 & 2.5 \\
\hline Widow & 0 & 0.0 \\
\hline \multicolumn{3}{|l|}{ Years of experience } \\
\hline$<1 \mathrm{yr}$ & 40 & 33.3 \\
\hline $1-<5 \mathrm{yrs}$ & 34 & 28.3 \\
\hline $5-<10$ yrs & 10 & 8.4 \\
\hline 10 and more & 36 & 30.0 \\
\hline Mean \pm SD & \multicolumn{2}{|c|}{$2.35 \pm 1.23$} \\
\hline
\end{tabular}

Table (2): Mean and standard deviation of quality of nursing work life of studied nurses at Assiut University Hospital ( $n=120)$.

\begin{tabular}{|l|c|}
\hline \multicolumn{1}{|c|}{ Factors } & Mean \pm SD \\
\hline Work Environment & $28.39 \pm 7.48$ \\
\hline Relations with managers & $18.69 \pm 5.10$ \\
\hline Work conditions & $34.79 \pm 7.42$ \\
\hline Job perception & $26.73 \pm 5.73$ \\
\hline Support Services & $13.61 \pm 4.07$ \\
\hline
\end{tabular}

Table (3): Mean \& standard deviation and range of organizational culture types of studied nurses at Assiut University Hospital (n=120).

\begin{tabular}{|l|c|c|}
\hline \multicolumn{1}{|c|}{ Culture Type } & Mean \pm SD & Range \\
\hline Strong & $56.7 \pm 3.9$ & $52-62$ \\
\hline Medium & $38.5 \pm 7.6$ & $26-51$ \\
\hline Weak & $17.8 \pm 3.6$ & $13-22$ \\
\hline
\end{tabular}


Table (4): Distribution of turnover intention items among studied nurses at Assiut University Hospital $(\mathbf{n}=\mathbf{1 2 0})$

\begin{tabular}{|c|c|c|c|c|c|c|c|c|c|c|c|c|c|c|}
\hline \multirow[t]{2}{*}{ Items } & \multicolumn{2}{|c|}{$\begin{array}{l}\text { Strongly } \\
\text { Disagree }\end{array}$} & \multicolumn{2}{|c|}{$\begin{array}{l}\text { Moderately } \\
\text { disagree }\end{array}$} & \multicolumn{2}{|c|}{$\begin{array}{c}\text { Slightly } \\
\text { Disagree }\end{array}$} & \multicolumn{2}{|c|}{ Uncertain } & \multicolumn{2}{|c|}{ Slightly Agree } & \multicolumn{2}{|c|}{$\begin{array}{l}\text { Moderately } \\
\text { Agree }\end{array}$} & \multicolumn{2}{|c|}{ Strongly agree } \\
\hline & No. & $\%$ & No. & $\%$ & No & $\%$ & No. & $\%$ & No. & $\%$ & No & $\%$ & No. & $\%$ \\
\hline 1. I plan to stay in my position & 0 & 0.0 & 14 & 11.7 & 16 & 13.3 & 22 & 18.3 & 16 & 13.3 & 9 & 7.5 & 43 & 35.8 \\
\hline $\begin{array}{l}\text { 2. I am quit sure I will leave my } \\
\text { position in the foreseeable future. }\end{array}$ & 22 & 18.3 & 5 & 4.2 & 16 & 13.3 & 42 & 35.0 & 12 & 10.0 & 10 & 8.3 & 13 & 10.8 \\
\hline $\begin{array}{l}\text { 3. Deciding to stay or leave my } \\
\text { position is not a critical issue for } \\
\text { me at this point in time. }\end{array}$ & 11 & 9.2 & 8 & 6.7 & 39 & 32.5 & 29 & 24.2 & 14 & 11.7 & 6 & 5.0 & 13 & 10.8 \\
\hline $\begin{array}{l}\text { 4. I know whether or not will be } \\
\text { leaving this hospital within a } \\
\text { short time. }\end{array}$ & 18 & 15.0 & 10 & 8.3 & 16 & 13.3 & 44 & 36.7 & 21 & 17.5 & 7 & 5.8 & 4 & 3.3 \\
\hline $\begin{array}{l}\text { 5. If I got another job offer } \\
\text { tomorrow, I would give it a } \\
\text { serious consideration. }\end{array}$ & 29 & 24.2 & 5 & 4.2 & 37 & 30.8 & 17 & 14.2 & 13 & 10.8 & 12 & 10.0 & 7 & 5.8 \\
\hline $\begin{array}{l}\text { 6. I have no intentions of leaving my } \\
\text { present position. }\end{array}$ & 31 & 25.8 & 11 & 9.2 & 16 & 13.3 & 24 & 20.0 & 31 & 25.8 & 4 & 3.3 & 3 & 2.5 \\
\hline $\begin{array}{l}\text { 7. I have been in my position about } \\
\text { as long as I wan } \\
\text { t to. }\end{array}$ & 19 & 15.8 & 8 & 6.7 & 33 & 27.5 & 34 & 28.3 & 13 & 10.8 & 7 & 5.8 & 6 & 5.0 \\
\hline 8. I am certain I will be staying here. & 6 & 5.0 & 7 & 5.8 & 14 & 11.7 & 52 & 43.3 & 12 & 10.0 & 8 & 6.7 & 21 & 17.5 \\
\hline $\begin{array}{l}\text { 9. I don't have any specific idea how } \\
\text { much longer I will stay. }\end{array}$ & 19 & 15.8 & 7 & 5.8 & 53 & 44.2 & 21 & 17.5 & 9 & 7.5 & 2 & 1.7 & 9 & 7.5 \\
\hline 10. I plan to hang on this job. & 36 & 30.0 & 8 & 6.7 & 21 & 17.5 & 22 & 18.3 & 22 & 18.3 & 9 & 7.5 & 2 & 1.7 \\
\hline $\begin{array}{l}\text { 11. There are big doubts in my mind } \\
\text { as to whether or not I will really } \\
\text { stay in this hospital. }\end{array}$ & 15 & 12.5 & 3 & 2.5 & 21 & 17.5 & 22 & 18.3 & 38 & 31.7 & 7 & 5.8 & 14 & 11.7 \\
\hline $\begin{array}{l}\text { 12. I plan to leave this position } \\
\text { shortly. }\end{array}$ & 16 & 13.3 & 6 & 5.0 & 16 & 13.3 & 30 & 25.0 & 18 & 15.0 & 11 & 9.2 & 23 & 19.2 \\
\hline
\end{tabular}

Table (5): Correlation matrix for scores of nurses' quality of work life, organizational culture and turnover intention.

\begin{tabular}{|r|c|c|c|}
\hline \multirow{2}{*}{ Scores } & \multicolumn{3}{|c|}{ Pearson correlation coefficient } \\
\cline { 2 - 4 } & \multicolumn{3}{|c|}{ Scores } \\
\cline { 2 - 4 } & Quality of work life & Organizational culture & Turnover intention \\
\hline Quality of work life & -- & $0.191^{*}$ & $0.259^{* *}$ \\
\hline Organizational culture & $0.191^{*}$ & -- & -0.148 \\
\hline Turnover intention & $0.259^{* *}$ & -0.148 & -- \\
\hline
\end{tabular}


Table (6): Best fitting multiple linear regression model for nurses' quality of work life scores.

\begin{tabular}{|c|c|c|c|c|c|}
\hline \multirow{2}{*}{ Variable } & \multicolumn{2}{|c|}{$\begin{array}{l}\text { Un-standardized } \\
\text { Coefficients }\end{array}$} & \multirow{2}{*}{$\begin{array}{c}\text { Standardized } \\
\text { Coefficients } \\
\text { Beta }\end{array}$} & \multirow[t]{2}{*}{ t-test } & \multirow{2}{*}{ p-value } \\
\hline & B & Std. Error & & & \\
\hline Constant & 48.641 & 18.162 & --- & 2.678 & $0.009 * *$ \\
\hline$\overline{\text { Age }}$ & -0.287 & 2.401 & -0.015 & -0.119 & 0.905 \\
\hline Department & 6.864 & 1.775 & 0.322 & -3.868 & $0.000 * *$ \\
\hline Educational qualification & 1.277 & 2.932 & 0.043 & 0.436 & 0.664 \\
\hline Marital status & -11.649 & 3.730 & -0.306 & -3.123 & $0.002 * *$ \\
\hline Years of experience & 3.880 & 2.221 & 0.227 & 1.747 & 0.083 \\
\hline Organizational culture score & 0.583 & 0.191 & 0.254 & 3.053 & $0.003 * *$ \\
\hline Turnover intention score & 0.811 & 0.237 & 0.285 & 3.424 & $0.001 * *$ \\
\hline
\end{tabular}

(**) Statistically significant at $p<0.001$

Table (1): Showed that the highest percentage were from General ICU, aged from 22 to less than 25 years, had Technical Institute of Nursing degree, single and had less than one year of experience $(35.0 \%, 59.2 \%, 47.5 \%, 51.7 \%, \& 33.3 \%)$ respectively .

Table (2): Illustrated that the highest mean and standard deviation of nurses' quality of work life factors were in work environment, work conditions, and job perception $(28.39 \pm 7.48 ; 34.79 \pm 7.42$ \& $26.73 \pm 5.73)$ respectively.

Table (3): Illustrated that the mean \& standard deviation and range of organizational culture types of studied nurses' were as follow: strong culture $56.7 \pm$ 3.9 with range from 52 to $62 \&$ Medium culture was $38.5 \pm 7.6$ with range from 26 to 51 and weak culture was $17.8 \pm 3.6$ with range from 13 to 22 .

Table (4): Showed that nearly two-thirds of nurses "strongly agree" for "I plan to stay in my position" $(35.8 \%)$ and more than one-quarter of nurses "slightly agree" and the same percentage was (strongly disagree) for "I have no intentions of leaving my present position" (25.8\%). Nearly to half of the nurses "slightly disagree" for "I don't have any specific idea how much longer I will stay" (44.2\%). More than one-quarter of nurses "strongly disagree" for "I plan to hang on this job" and " Slightly Agree" for "There are big doubts in my mind as to whether or not I will really stay in this hospital" $30.0 \% \&$ $31.7 \%$.) respectively .

Table (5): Displayed that there was a significant correlation between quality of work life and organizational culture $(r=0.191, p<0.05)$. There was a positive correlation with a highly statistically significant relation between quality of work life and turnover intention $(\mathrm{r}=0.259, \mathrm{P}<0.01)$. While, there was a negative correlation between turnover intention and organizational culture $(\mathrm{r}=-0.148)$.

Table (6): Depicted that best fitting multiple regression model for nurses' quality of work life scores was highly significant in relation to department (t-test $=-3.868, \quad \mathrm{r}=0.000, \mathrm{P}<0.01$ ), marital status (t-test $=-3.123, \mathrm{r}=0.002, \mathrm{P}<0.01)$, organizational culture score $(\mathrm{t}$-test $=3.053, \mathrm{r}=0.003$, $\mathrm{P}<0.01)$, and turnover intention score $(\mathrm{t}$-test $=3.424$, $\mathrm{r}=0.001, \mathrm{P}<0.01)$.

\section{Discussion}

Today, concept quality of work life has become an important issue and many studies have been published on this topic which basically describes the methods by which an organization can ensure the holistic well-being of an employee instead of only focusing on work-related aspects (Khani et al., 2008). The high quality of work life is essential for organizations to achieve high performance and growth in profitability and to continue to attract and retain employees (Sandrick, 2003\& Ruzevicius, 2006). As a general rule, the quality of work depends on a proper work environment in which nurses' work. Actually, it is an essential issue in their patients' outcomes and turnover and it plays a significant role in their satisfaction (Institute of Medicine, 2004).

The present study findings revealed that the highest mean and standard deviation for nurses' quality of work life factors were in work environment, work conditions, and job perception (Table, 2). This might be due to ineffective leadership style who don't know the importance of positive work condition and environment and how to deal with problems in them and change the nurses' perceptions toward their jobs. These results were in agreement with Kotze, (2005) who stated that quality of work life is often 
considered in two directions, one is the removal of negative aspects of work and working conditions and another direction is the modification of work and working conditions to enhance the capability of employees.

In addition, The study findings is supported by previous findings of Almalki et al., (2012) who found that the major influencing factors in quality of life were unsuitable working hours, lack of facilities for nurses, inability to balance work with family needs, poor staffing, management and supervision practices, lack of professional development opportunities, and an inappropriate working environment, and lack of motivating climate.

Moreover, Khani et al., (2008) reported that external factors such as salary and the image of nursing were sources of dissatisfaction for nurses in various organizations and another significant finding by Jayakumar, (2012) which clarified that salary was the strong predicator for job satisfaction and quality of nursing work life.

As found in the present study, single nurses were having significant relation with quality of nurses work life than the married nurses. This finding is supported by Al-Enezi et al., (2009) who clarified that one possible explanation for the finding may be that single nurses were younger compared to other groups so they may not have the required skills to cope with challenges at work when they differ from expectations. While, Nayeri et al., (2011) and Dargahi et al., (2012) found that quality of work life has no significant relationship with marital status. However, Tayebeh et al., (2014) found that more than half of nurses reported that they had a moderate level of quality of working life while more than onethird had undesirable and good quality of working life, respectively. Nurses with associate degrees reported a better quality of working life than others. A significant relationship was found between variables such as level of education and years of work experience. No significant differences were observed between the quality of working life score of nurses with employment status, salary, age, gender and marital status.

From study findings, the culture in the Assiut University Hospital was strong as a predominant organizational culture as shown in (table, 3). This might be attributed to the hospital policy makers who were clear in how the jobs contribute to organizational goals, there were warmth and support for personnel is a value norm, employees are expected to acquire real knowledge and mastery, not political alliances before they can be promoted, and organization values emphasize what the organization must do well to succeed in a changing environment.
In this respect, Abdalla , (2009) stated that strong or positive culture or constructive culture that which members are encouraged to interact with others and to approach tasks in proactive ways that will help them to meet their satisfaction needs. Meanwhile, other both types of culture (medium, weak or passive aggressive and aggressive defensive culture ) that which member interact in reactive ways and approach tasks in forceful ways to protect their status.

There was a significant correlation between quality of work life and organizational culture. There was a positive correlation with a highly statistically significant difference between the quality of work life and intent to turnover. While, there was a negative correlation between turnover intention and organizational culture (Table, 5). Nurses' quality of work life scores was highly statistically significant relation with the department, marital status, organizational culture score, and turnover intention score (Table, 6).

These findings were consistent with the findings of Gifford et al., (2002) who investigated the relationships between unit organizational culture and several important job-related variables for nurse retention in the labor and delivery units of seven hospitals. The results of the study showed that unit organizational culture affects nurses' quality of work life factors and that human relation cultural values are positively related to organizational commitment, job involvement, empowerment, and job satisfaction, and negatively related to intent to turnover.

While, Mosadeghrad, (2013) clarified that when introducing quality of work life to various cultures, attention must be given to the relative individual versus collective emphasis. Organizations operating in countries low on individualism may tend to deemphasize individual incentives and rewards and prefer to provide group incentives and opportunities for group problem-solving. In such countries with low individualism, organizational qualities of worklife programs are likely to be group oriented and somewhat paternalistic in flavor. However, in nations high on individualism such as Iran, individual decisions are thought to be better than group decisions and as a result, individual initiative is socially encouraged, and a strong importance is attached to freedom and challenge in jobs.

\section{Conclusions}

- A positive correlation between quality of nurses work life and organizational culture with statistically significant relation and between the quality of nurses work life and intent to turnover. While, there was a negative correlation between intent to turnover and organizational culture . 
- The quality of work life scores had statistically significant relations with the department, marital status, organizational culture and turnover intention among studied nurses.

\section{Recommendations}

- Workshops on the quality of work life skills for nurses and nurse managers should be done periodically.

- Nursing studies are required to be done on the quality of work life, organizational commitment, and retention of nurses.

- The policies are crucial strategic short-term decisions, which help to achieve organizational long-term objectives that lead to being a strong culture in the hospital.

- Nurses should encourage participating in nursing committees and becoming decision-makers to decrease intent to turnover from the hospital.

- The organization should revise its performance evaluation system to ensure clinical excellence of nurses .

- Provide safety measures to protect health care providers from occupational health hazards.

\section{References}

1. Abdalla, S., (2009): Relationship between organizational culture and ethics work satisfaction among Baccalaureate nurses at main Assiut University Hospital, The New Egyptian Journal of Medicine, vol. (40), No. (1), Pp. 45 59.

2. Adhikari, D., \& Gautam, D., (2010): Labour legislations for improving quality of work life in Nepal. Int. J. Law Manage., 52: 40-53.

3. Al-Enezi, N., Chowdhury, R., Shah, M., AlOtabi M., (2009): Job satisfaction of nurses with multicultural backgrounds: a questionnaire survey in Kuwait. Appl Nurs Res. 22(2): Pp. 94 100.

4. Almalki M., FitzGerald G., \& Clark M., (2012): Quality of work life among primary health care nurses in the Jazan region, Saudi Arabia: a crosssectional study. Human Resources for Health; 10:30.

5.Almalki, M., (2012): Quality of work life and turnover intention in primary health care organizations; A cross-sectional study of Registered nurses in Saudi Arabia, Published Doctoral degree thesis.

6. Brooks, B., (2001): Development of an instrument to measure quality of nursing work life. Doctoral dissertation, University of Illinois at Chicago.

7. Cameron, k., \& Quinn, R., (1999): Diagnosing and Changing Organizational Culture Based on the Competing Values Framework. AddisonWesley Publishing Company, Inc.

8. Cole D., Robson, L., Lemieux-Charles, L., McGuire, W., Sicotte, C., \& Champagne, F., (2005): Quality of working life indicators in Canadian health care organizations: a tool for healthy, health care workplaces? Occup. Med. (Lond) 55, 54-59.

9. Connell, J., (2009): Call centers, quality of work life and HRM practices: An in-house/outsourced comparison. Employee Relations, 31: 363-381.

10. Dargahi, H., Changizi, V., Jazayeri Gharabagh, E. (2012): Radiology employees' quality of work life. Acta Med Iran.50 (4):250-6.

11. Drobnic, S., Beham, B., \& Prag, P., (2010): Good job. Good Life? Working Conditions and Quality of Life in Europe. Social Indicator Research, 99, Pp. 205- 225.

12. Farjad, H. \& Varnous, S. (2013): Study of relationship of quality of work life (OWL) and Organizational Commitment. International Journal of Contemporary Research in Business,4, 9, Pp. 449 - 456.

13. Gifford, B., Zammuto, R., \& Goodman, E., (2002): The relationship between hospital unit culture and nurses' quality of work life. J. Health Care Management, 47: Pp.13-26.

14. Hinshaw, A., \& Atwood, J., (1984): Anticipated turnover among nursing staff study: final report: National center for nursing research. National Institute of Health.

15. Hsu, M., \& Kernohan, G., (2006): Dimensions of hospital nurses' quality of working life. Journal of Advanced Nursing, 54: 120-131.

16. Institute of Medicine, (2004): Keeping Patients Safe. Transforming the Work Environment of Nurses. Washington. DC; National Academy Press; Pp.335-50.

17. Jayakumar, A., \& Kalaiselvi, K., (2012): Quality of Work life : An Overview, International Journal of Marketing, Financial Services and Management Research, vol.: 1, no: 10, pp. 140-151. 30.

18. Khani A., Jaafarpour M., \& Dyrekvandmogadam A., (2008): Quality of nursing work life. J Clin Diagn Res; 2(6):Pp.1169-1174.

19. Khodayarian M., Vanaki Z., Navipour H., Vaezi A., (2008): The effects of designed clinical competency-based advancement program on the CCU nurses' quality of work life. Daneshvar Med.15 (75):Pp.15-26.

20. Korunka, C., Hoonakker \& Carayon, P., (2008): Quality of Working Life and Turnover Intention in Information Technology Work. 
Human Factors and Ergonomics in Manufacturing, 18, 4, 408-423.

21. Kotze, M., (2005): The nature and development of the construct quality of work life. Acta Academia, 37(2), Pp. 96-122.

22. Kreitner R., Kinicki A., (2008): Organizational Behavior. 8th Edition. New York: McGrawHill/Irwin.

23. Marques, B., \& Huston, C., (2009): Leadership roles and management functions in nursing: theory and application, $6^{\text {th }}$ edition, Lippincott Williams \& Wilkins publisher, Pp. 278-280.

24. Mohammadi, A., Sarhanggi, F., Ebadi, A., Daneshmandi, M., Reiisifar, A., Amiri, F., \& Hajamini, Z., (2011): Relationship between psychological problems and quality of work life of Intensive Care Units Nurses, Iranian Journal of Critical Care Nursing, Autumn, Volume 4, Issue 3, Pp. $135-140$.

25. Mosadeghrad, A., (2013): Quality of working life: An antecedent to employee turnover intention. International Journal of Health Policy and Management, 1:Pp. 43-50.

26. Mosadeghrad, A., Ferlie, E., \& D., Rosenberg, D.(2011): A study of relationship between job stress, quality of working life and turnover intention among hospital employees. Health Serv. Manage. Res., 24: 170-181.

27. Nayeri, N., Salehi T., Noghabi, A., (2011): Quality of work life and productivity among Iranian nurses. Contemporary Nurse. 39(1):10618.

28. Ruzevicius, J., (2006): Quality models and their application for improvement of organizations activities. Forum Ware International, 1, Pp.1624.

29. Sandrick, K., (2003): "The emphasis on employees - as an award-winning employer", Baptist health care has distant memories of the workforce shortage. Trustee: January; Pp. 6-10.

30. Tayebeh, M., Farzaneh, M., and Ismail, A., (2014): Quality of Working Life of Nurses and its Related Factors. Nursing and Midwifery Studies. 3(2).Pp.1-5.

31. Ugur, E., \& Abaan, S., (2008): Nurses' Opinions about Their Quality of Work life and Related Factors. Turkish Clinics Journal of Medical Sciences 28, 297-310.

32. Waters, V., (2004): Cultivate corporate culture and diversity: Create and maintain a thriving environment in the midst of institutional change. Nursing Management, 35(1), Pp. 36-50.

33. Way, M., (2006): Organizational characteristics and their effect on health. Nursing Economics, 24(2), Pp. 67-77. 